\title{
Numerical Study of Natural Convection in a Three-dimensional Cavity Filled with Nanofluids
}

\author{
Mohamed Sannad ${ }^{1}$, Btissam Abourida ${ }^{2}$, Lahoucine Belarche ${ }^{3}$, Hicham Doghmi ${ }^{4}$ \\ ${ }^{1}$ National School of Applied Sciences, Ibn Zohr University \\ Agadir, Morocco \\ ${ }^{2}$ National School of Applied Sciences, Ibn Zohr University \\ Agadir, Morocco \\ ${ }^{3}$ National School of Applied Sciences, Ibn Zohr University \\ Agadir, Morocco \\ ${ }^{4}$ National School of Applied Sciences, Ibn Zohr University \\ Agadir, Morocco
}

\begin{abstract}
Natural convection in a cubic cavity filled with nanofluids and discretely heated, is studied numerically using a threedimensional finite volume formulation. Two heating square portions are placed on the vertical wall of the enclosure, while the rest of the considered wall is adiabatic. These sections are heated with a constant uniform temperature $T_{H}$ while the opposite vertical wall is maintained at a cold uniform temperature $\mathrm{T}_{\mathrm{C}}$. The other walls are adiabatic. The fluid flow and heat transfer in the cavity are studied for different sets of the governing parameters, namely the Rayleigh number $10^{3} \leq \mathrm{Ra} \leq$ $10^{5}$, type of nanofluid copper $(\mathrm{Cu})$, alumina $\left(\mathrm{Al}_{2} \mathrm{O}_{3}\right)$ and titanium $\left(\mathrm{TiO}_{2}\right)$ and volume fraction $0.0 \leq \Phi \leq 0.2$ The heating sections dimension $\mathrm{E}$ and the Prandtl number Pr are respectively fixed to 0.15 and 6.2 (water).
\end{abstract}

Keywords: Natural convection, Nanofluids, Thermophysical properties, Heat transfer, Three dimensional cavity.

\section{Introduction}

Flow and heat transfer induced by natural convection have been considerably studied these last decades because of its direct application in various fields of engineering such as the air conditioning, the energy efficiency, the cooling of the electronic components etc..... The previous works had mostly focused on the improvement of heat transfer induced by natural convection, which led to the development of a new researches area based on the molecular structure of the fluid. Hence, the previously used fluids can be substituted by nanofluids, which are colloidal solutions composed by particles of nanometric size in suspension in a conventional fluid. The term nanofluid was proposed for the first time in 1995 by Choi [1] who opened the door to a new technology which presented higher thermal properties. In fact, this concept has been proposed as a technique to improve the performance of the thermal transmission of conventional fluids. Thus, the interest presented by the nanofluids has given rise to numerous studies which focused on the determination of their thermophysical properties such as the thermal conductivity, specific heat and dynamic viscosity and their impact on the flow and heat transfer.

Putra et al. [2] have studied experimentally the behavior of nanofluids such as $\left(\mathrm{Al}_{2} \mathrm{O}_{3}\right.$-water $)$ and $(\mathrm{CuO}$-water $)$ inside a horizontal cylinder submitted to constant temperatures. They observed that the heat transfer decreases when the concentration of nanoparticles increases and becomes more significant in the case of nanofluid (CuO-water).

Khanafer et al. [3] studied the improvement of heat transfer within a differentially heated enclosure. The horizontal walls are assumed to be isolated, non conductive and impermeable to the mass transfer.

The nanofluid in the enclosure is incompressible Newtonian and laminar flow and the nanoparticles are assumed to have a shape and a uniform size. In addition, it is assumed that both the liquid phase and nanoparticles are in a state of thermal equilibrium and flow at the same speed. The Left vertical wall is maintained at a high temperature $T_{h}$ while the right one is maintained at a low temperature $T_{1}$. Thermophysical properties of the nanofluid are assumed to be constant, except for the variation of density in the force of buoyancy, which is based on the 
approximation of Boussinesq. They authors used the Brinkman model [4] to evaluate the viscosity of the nanofluid and the wasp model [5] for the thermal conductivity of the actual nanofluid. They studied numerically the improvement of heat transfer in a bidimensional enclosure, for different Grashof numbers and volume fractions.

The results show that compared to a pure fluid, the nanoparticles in suspension increase significantly the rate of heat transfer for given Grashof number. In addition, the heat transfer is enhanced by an increasing volume fraction of the nanoparticles. Hence, the presence of nanoparticles in the fluid changes the structure of the fluid flow and hest transfer. The authors have also proposed a correlation of the heat transfer rate expressed by Nusselt number for different Grashof number, and different volume fractions of nanoparticles.

Oztop and Abu-Nada [6] have studied numerically the natural convection in the rectangular enclosures partially heated. They analyzed the effect of the volumic concentration, the type of nanoparticles, Rayleigh number, the length and the position of the heat source and the aspect ratio of the enclosure.

The results indicated that the improvement of the heat transfer depends on the governing parameters and has the same trend as that obtained by Jou and Tzeng [7]. Hence, it has been found that the position of the heat source affects significantly the thermal and dynamical behavior of the nanofluid. In addition, the increase of heat transfer within the cavity is more important when for low aspect ratios.

The influence of the magnetic field on the natural convection has been studied in the case of nanofluids in 2011 by Ghasemi and al. [8]. These authors used the finite volumes method to study the convective behavior of the nanofluid $\left(\mathrm{Al}_{2} \mathrm{O}_{3}\right.$-water $)$ in a square cavity differentially heated and submitted to a horizontal constant magnetic field. The results showed that the heat transfer decreases with the increase in the Hartmann number and that the increase in the volumic concentration, can lead to either an improvement or a decrease of the thermal heat transfer according to the chosen values of the Hartmann number and the Rayleigh number. This work of Ghasemi and al. [9] has been followed by another study of the same problem, conducted by Nemat et al. [10], who used the Boltzmann method to achieve the numerical simulations. The obtained results indicate that the average Nusselt number improves with the increase of the volume fraction of the nanoparticles. However, the effect of this parameter becomes less important in the presence of a high magnetic field.

Mahmoudi et al. [11] presented a numerical investigation on the natural convection in a square enclosure filled with nanofluid ( $\mathrm{Cu}$-water). A single heating source, generating a constant heat flux, is placed on the left vertical wall of the enclosure.The other vertical wall is maintained at constant cold temperature, while the other walls are thermally isolated.

The same models as those used by Guiet and al. [12], are applied to evaluate the viscosity and the thermal conductivity of the nanofluid. The effects of solid concentration of the nanofluid, the Rayleigh number, the position and the geometry of the heat source on the heat transfer are studied. The results show that the flow and heat transfer are significantly affected by the heating source dimension. Hence, the average Nusselt number decreases when the length of the heating increases.

On the other hand, the Nusselt number increases linearly with the increase of solid concentration of the nanofluid.

The same results have been found by Ravink et al. [13], who showed that the heat transfer is significantly enhanced by the increase of the volumic fraction of the nanofluid. This improvement is evident, compared to the case of pure water and also in the case of dominant conduction heat transfer.

The previous review shows the existence of numerous theoretical and practical studies, conducted on this subject. However, most of these available works considered the case of two-dimensional natural convection while the three-dimensional approach allows a better and more realistic simulation of the fluid flow and heat transfer within the cavity [13].Hence, the purpose of the present investigation is to study numerically the laminar natural convection in a cubical enclosure filled with nanofluid and heated from the side with two heating square sections. The temperature of the opposite vertical wall is maintained at a cold uniform temperature. The temperature distributions, the velocity patterns and the heat transfer rates are analyzed and discussed in this paper.

\section{Problem Formulation}

The schematic of the considered configuration is shown in fig 1. The model consists of a three-dimensional cavity. Two heating sources are integrated on the left vertical wall of the cavity and maintained at the temperature $T_{H}$. The rest of the considered wall is adiabatic while the temperature of the opposite vertical wall is maintained at a uniform cold temperature $\mathrm{T}_{\mathrm{C}}$. The cavity dimensions are $\mathrm{L}=\mathrm{H}=\mathrm{W}=1$ while the length of the square sections is $\mathrm{E}=0,15$. 


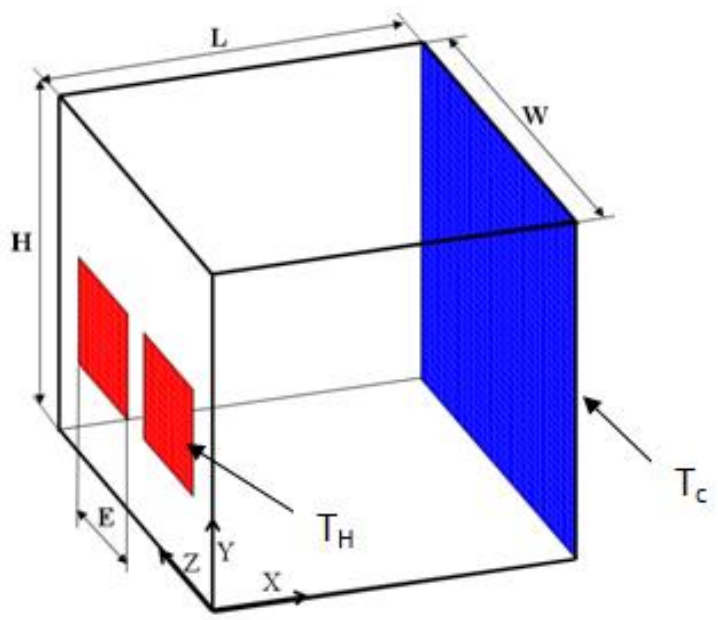

Fig 1: Studied configuration and coordinates

The governing equations are discretized by the finite volume method, adopting the Boussinesq approximation and neglecting the viscous dissipation. The physical parameters are given by the following equations:

- The density:

$$
\rho_{n f}=(1-\phi) \rho_{f}+\phi \rho_{n p}
$$

- The heat capacitance of the nanofluid [14]:

$$
\left(\rho C_{p}\right)_{n f}=(1-\phi)\left(\rho C_{p}\right)_{f}+\phi\left(\rho C_{p}\right)_{n p}
$$

- Thermal expansion coefficient:

$$
\beta_{n f}=(1-\phi) \beta_{f}+\phi \beta_{n p}
$$

- The dynamic viscosity of the nanofluid:

Brinkman [4] has extended the Einstein formula to cover a wide range of volumetric concentrations.

$$
\mu_{n f}=\frac{\mu_{f}}{(1-\phi)^{2.5}}
$$

- Thermal diffusivity of nanofluids:

$$
\alpha_{n f}=\frac{k_{n f}}{\left(\rho C_{p}\right)_{n f}}
$$

- The thermal conductivity of nanofluids: The formula of Maxwell [15] is given by:

$$
\frac{k_{n f}}{k_{f}}=\frac{k_{n p}+2 k_{f}-\left[2\left(k_{f}-k_{n p}\right) \phi\right]}{k_{n p}+2 k_{f}+\left[\phi\left(k_{f}-k_{n p}\right)\right]}
$$

$k_{n f}, k_{f}$ and $k_{n p}$ are respectively the thermal conductivities of the nanofluid, of the basic fluid and solid nanoparticles.

In the previous expressions, indices $\mathrm{f}$ and $\mathrm{np}$ represent respectively basic fluid and dispersed nanoparticles. The thermo-physical properties of the basic fluid, water, and the considered nanoparticles are given in Table I.

In order to obtain dimensionless equations, the following parameters are then used:

$$
\begin{aligned}
& X=\frac{x}{H} ; Y=\frac{y}{H} ; Z=\frac{z}{H} ; U=\frac{u H}{\alpha_{f}} ; V=\frac{v H}{\alpha_{f}} ; \\
& W=\frac{w H}{\alpha_{f}} ; \tau=\frac{t \alpha_{f}}{H^{2}} ; P=\frac{\left(p+\rho_{0} g y\right) H^{2}}{\rho_{n f} \alpha_{f}^{2}} ; \theta=\frac{T-T_{r e f}}{T_{H}-T_{c}} \\
& ; T_{r e f}=\frac{T_{C}+T_{H}}{2} .
\end{aligned}
$$

Table 1:Thermophysical properties of water and of nanoparticles

\begin{tabular}{|c|c|c|c|c|}
\cline { 2 - 5 } \multicolumn{1}{c|}{} & $\rho\left(\mathrm{kg} \cdot \mathrm{m}^{-3}\right)$ & $\beta\left(\mathrm{K}^{-1}\right)$ & $\mathrm{k}\left(\mathrm{W} \cdot \mathrm{m}^{-1} \cdot \mathrm{K}^{-1}\right)$ & $\mathrm{C}_{\mathrm{p}}\left(\mathrm{J} \cdot \mathrm{kg}^{-1} \cdot \mathrm{K}^{-1}\right)$ \\
\hline Pure Water & 997.1 & $21 \times 10^{-5}$ & 0.613 & 4179 \\
\hline $\mathrm{AL}_{2} \mathrm{O}_{3}$ & 3970 & $0.85 \times 10^{-5}$ & 40 & 765 \\
\hline $\mathrm{Cu}$ & 8933 & $1.67 \times 10^{-5}$ & 400 & 385 \\
\hline $\mathrm{TiO}_{2}$ & 4250 & $0.90 \times 10^{-5}$ & 8.9538 & 686.2 \\
\hline
\end{tabular}

Hence, the obtained dimensionless governing equations are:

$$
\frac{\partial U}{\partial X}+\frac{\partial U}{\partial Y}+\frac{\partial U}{\partial Z}=0
$$

$$
U \frac{\partial U}{\partial X}+V \frac{\partial U}{\partial Y}+W \frac{\partial U}{\partial Z}=-\frac{\partial P}{\partial X}+\frac{\mu_{n f}}{\alpha_{f} \rho_{n f}}\left(\frac{\partial^{2} U}{\partial X^{2}}+\frac{\partial^{2} U}{\partial Y^{2}}+\frac{\partial^{2} U}{\partial Z^{2}}\right)
$$

$$
\begin{gathered}
U \frac{\partial V}{\partial X}+V \frac{\partial V}{\partial Y}+W \frac{\partial V}{\partial Z}=-\frac{\partial P}{\partial Y}+R_{a} * P_{r} * \theta * \frac{\rho_{f} \beta_{n f}}{\rho_{n f} \beta_{f}} \\
+\frac{\mu_{n f}}{\alpha_{f} \rho_{n f}}\left(\frac{\partial^{2} V}{\partial X^{2}}+\frac{\partial^{2} V}{\partial Y^{2}}+\frac{\partial^{2} V}{\partial Z^{2}}\right) \\
U \frac{\partial W}{\partial X}+V \frac{\partial W}{\partial Y}+W \frac{\partial W}{\partial Z}=-\frac{\partial P}{\partial Z}+\frac{\mu_{n f}}{\alpha_{f} \rho_{n f}}\left(\frac{\partial^{2} W}{\partial X^{2}}+\frac{\partial^{2} W}{\partial Y^{2}}+\frac{\partial^{2} W}{\partial Z^{2}}\right) \\
U \frac{\partial \theta}{\partial X}+V \frac{\partial \theta}{\partial Y}+W \frac{\partial \theta}{\partial Z}=\frac{\alpha_{n f}}{\alpha_{f}}\left(\frac{\partial^{2} \theta}{\partial X^{2}}+\frac{\partial^{2} \theta}{\partial Y^{2}}+\frac{\partial^{2} \theta}{\partial Z^{2}}\right)
\end{gathered}
$$


Where $R a$ and $P r$ are respectively the Rayleigh number and the Prandtl number defined by:

$$
R_{a}=\frac{g \beta_{f}\left(T_{H}-T_{c}\right) H^{3}}{\alpha_{f} v_{f}} \text { and } \operatorname{Pr}=\frac{v_{f}}{\alpha_{f}}
$$

The adopted thermal boundary conditions are:

$\theta=-0.5$, for $X=1$; on the cold wall

$\theta=0.5$, for $X=0$ on the heating portions;

$\frac{\partial \theta}{\partial n}=0$ On the adiabatic walls

Where $\mathrm{n}$ refers to the normal to the considered wall.

The adopted hydrodynamic boundary conditions are:

$U=V=W=0$ for all walls.

The local Nusselt number defined as:

$$
N u_{l}(y, z)=\frac{k_{n f}}{k_{f}} \vec{\nabla} \theta \cdot \vec{e}_{x}
$$

The average Nusselt number, $\mathrm{Nu}_{\mathrm{a}}$, is defined as the integral of the temperature flux through a wall. For a nanofluid at vertical cold wall, it is written as:

$$
N u_{a}=\frac{k_{n f}}{k_{f}} \int_{S} \vec{\nabla} \theta \cdot \vec{e}_{x} d y d z
$$

\section{Numerical method}

The equations system (7-11) associated with the above boundary conditions are solved numerically using the finite volumes method [16] and power law schema. The conservation equations associated with the continuity equation are resolved using the SIMPLEC algorithm. The resolution of the Algebric System is then based on the The Alternating Direction Implicit scheme (ADI).

The tri-diagonal system, obtained in each direction, is then solved using the Thomas algorithm. The convergence of the numerical code is established at each time step according to the following criterion:

$$
\sum_{i, j, k=1}^{i \max , j \max , k \max } \frac{\left|\phi_{i, j, k}^{n+1}-\phi_{i, j, k}^{n}\right|}{\left|\phi_{i, j, k}^{n}\right|} \leq 10^{-5}
$$

Where $\Phi$ represents one of the variables $(U ; V ; W ; T ; P)$ and $\mathrm{i} ; \mathrm{j}$ and $\mathrm{k}$ are the grid positions.

$\mathrm{n}$ represents the number of time steps.

To check the effect of the grid size, preliminary tests have been conducted for different sets of the governing parameters. The results obtained are relative to the nanofluid water- $\mathrm{Al}_{2} \mathrm{O}_{3}(\Phi=0.1)$ and $R a=10^{3}$ are presented in Table II. Hence, the non-uniform staggered grid of $41 \times 41 \times 41$ nodes was estimated to be appropriate for the present study since it permits a good compromise between the computational cost (a significant reduction of the execution time) and the accuracy of the obtained results. Thereafter, the present code has been validated by comparing its results with those published by previous studies in the case natural convection in a cavity filled with nanofluid. The tests were conducted based on the results of Ravnik et al. [13]. Table III presents a comparison between the results of two studies in term of average Nusselt number for different sets of the governing parameters and different nanofluids. The results are found to be in excellent agreement with a maximum difference of $3.59 \%$. Three-dimensional isotherm contours were also produced and found to be in good agreement with those reported previously in references [13].

Table 2: Variation of the Nusselt number with different grids

\begin{tabular}{|l|l|l|l|l|l|}
\hline Grids & $21 \times 21 \times 21$ & $31 \times 31 \times 31$ & $41 \times 41 \times 41$ & $51 \times 51 \times 51$ & $61 \times 61 \times 61$ \\
\hline $\mathrm{Nu}_{\mathrm{a}}$ & 1.367004 & 1.357282 & 1.353103 & 1.350895 & 1.349503 \\
\hline
\end{tabular}

Table 3: Comparison of the average Nusselt number between our results and those of Ravnik et al.[13]

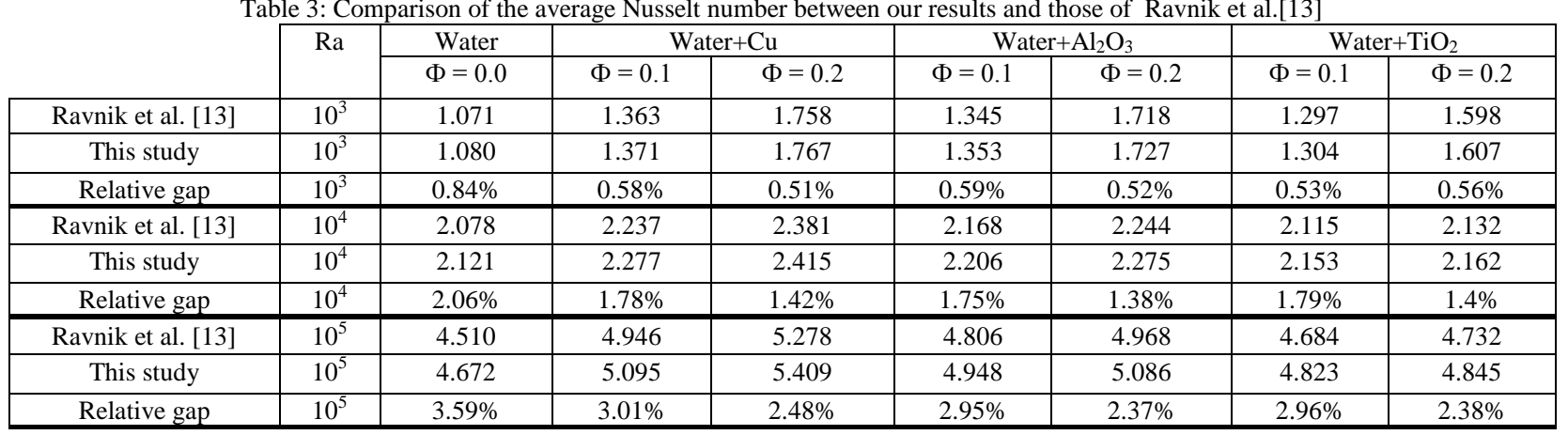




\section{Results and Discussions}

The results presented in this section were obtained for Rayleigh numbers Ra ranging between $10^{3}$ and $10^{5}$ and the volume fraction ranging between 0 and 0,2 . The considered nanoparticles are either copper $(\mathrm{Cu})$ or alumina $\left(\mathrm{Al}_{2} \mathrm{O}_{3}\right)$ or titanium $\left(\mathrm{TiO}_{2}\right)$.

(a)

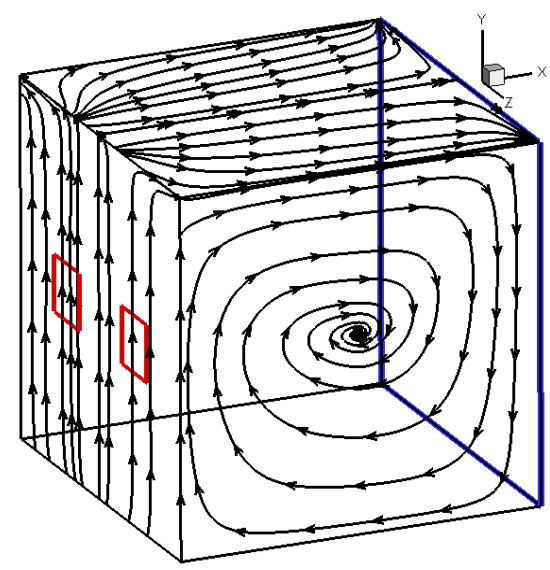

Fig 2: (a) 3D Streamlines and (b) 3D isotherms for $\mathrm{Ra}=10^{5}$ and $\Phi=0.2$

\subsection{Isotherms}

In order to visualize the flow and the temperature distribution within the studied cavity, 3D streamlines and isotherms are presented respectively in fig 2(a) and 2(b), for $\mathrm{Ra}=10^{5}$ and $\Phi=0.2$. The figures show that the fluid flow consists of a big and unique cell occupying the entire cavity. The fluid motion leads the heat from the active sections through the cavity. High values of the temperature are normally observed in the upper part of the enclosure as shown by the corresponding isotherms.

For more visibility of the fluid motion and heat transfer, streamlines and isotherms are presented at the mid-plane of the cavity $(Z=0.5)$. Further flow presentations were produced for different plans in the cavity, and show that the flow consists of a single cell, turning clockwise and presenting a symmetry relative to the center of the cavity $(\mathrm{Z}=0.5)$ for the considered cases. Hence the Fig 3 represents the isotherms obtained in $\mathrm{Z}$ plan for the different values of $\mathrm{Ra}$ and a volume fraction of nanoparticle $\Phi$ equal to 0.2 .
The dimension of the heating sections $\mathrm{E}$ and the Prandtl number $\operatorname{Pr}$ were respectively fixed at $\mathrm{E}=0.15$ and 6.2 (water). Isotherms and streamlines are presented in order to illustrate the nanofluid motion and the heat transfer within the cavity. The variation of the average Nusselt number with the governing parameters was also investigates.

(b)

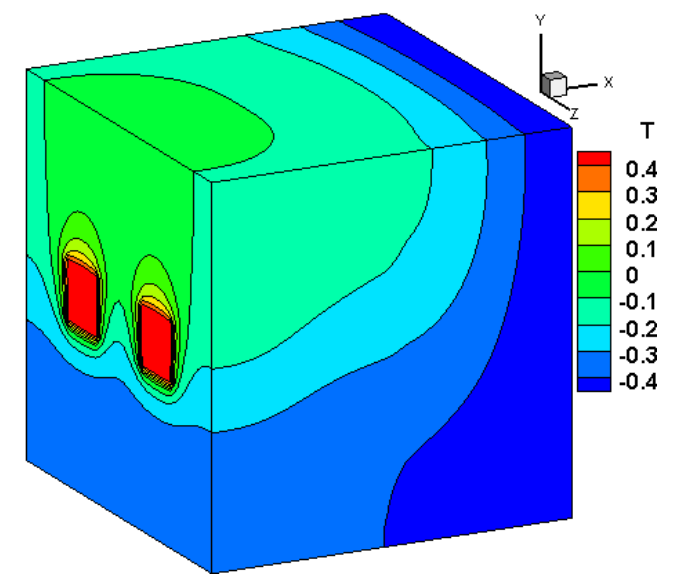


temperature distribution. Considering each nanofluid, the variation of the volume fraction has no effect in the central part of the enclosure. However, larger differences are shown near the horizontal walls. This is due to the rotating nature of the flow inside the enclosure. The thermal fields are also characterized by a horizontal stratification within the cavity and by high thermal gradients on the active walls.

$$
\mathrm{Ra}=10^{3}
$$
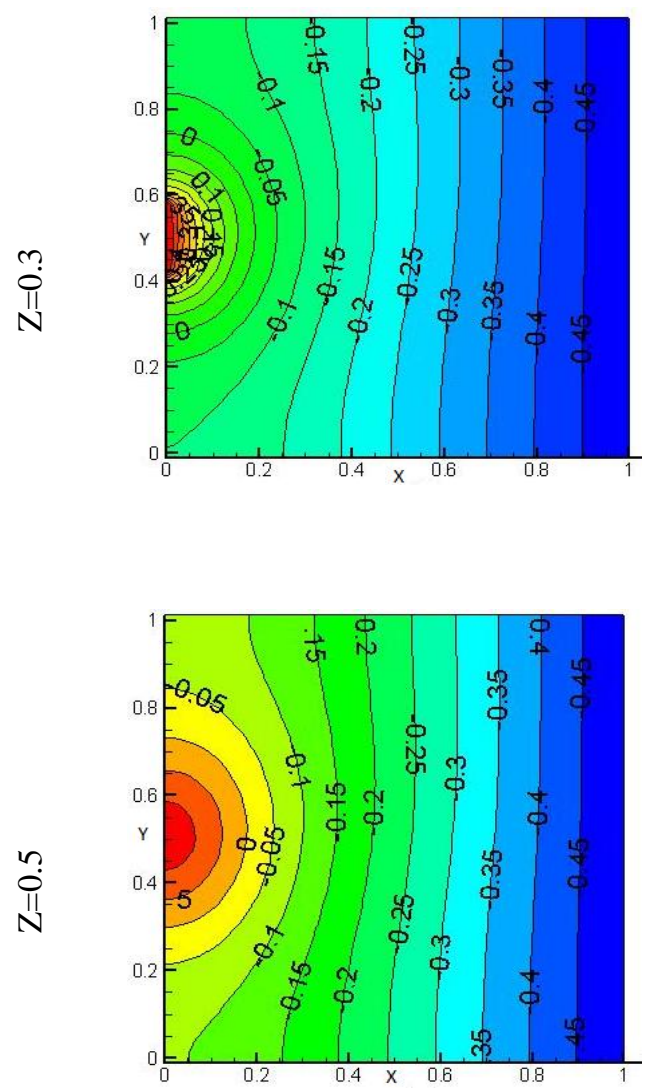

$\mathrm{Ra}=10^{5}$
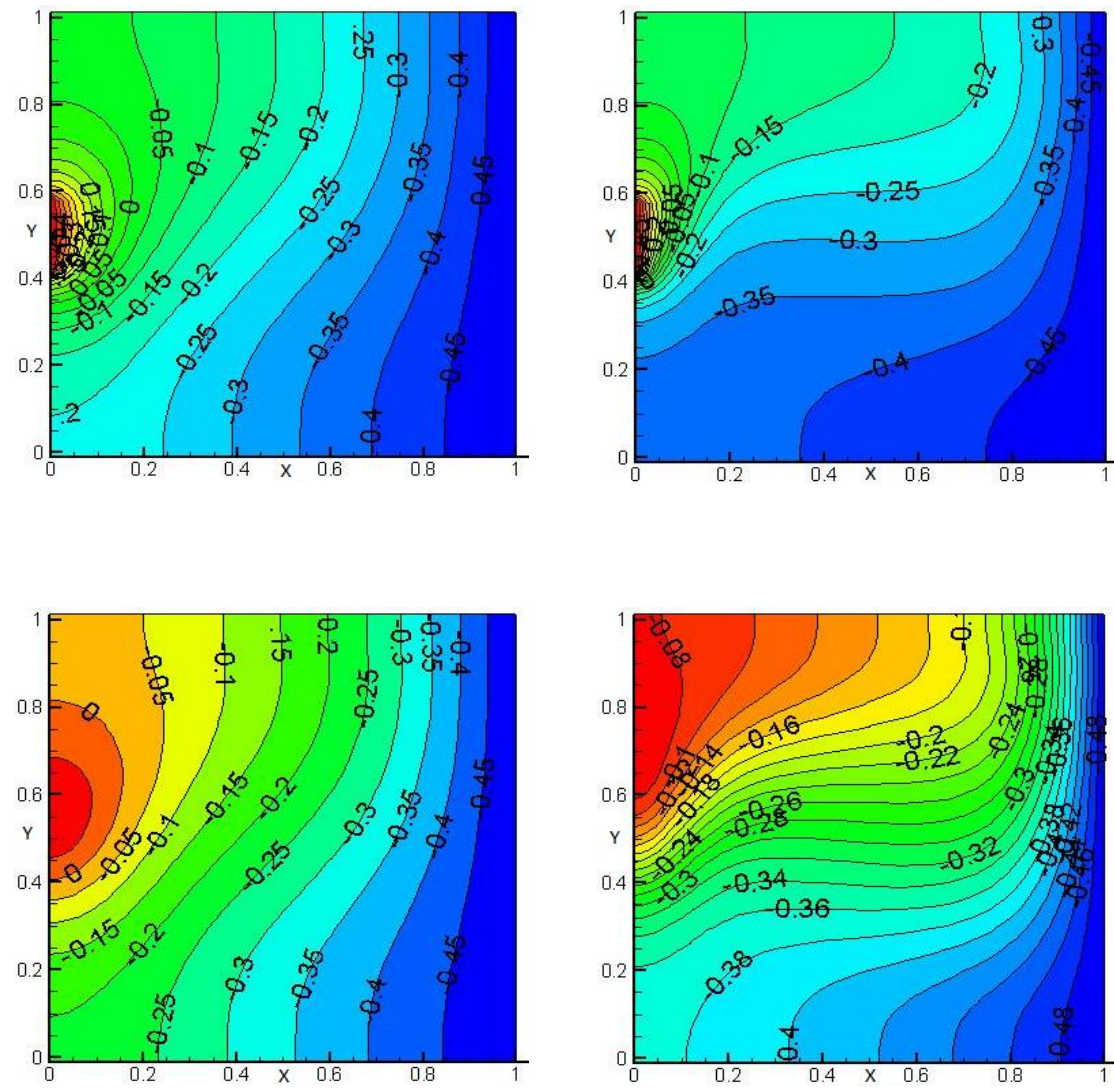
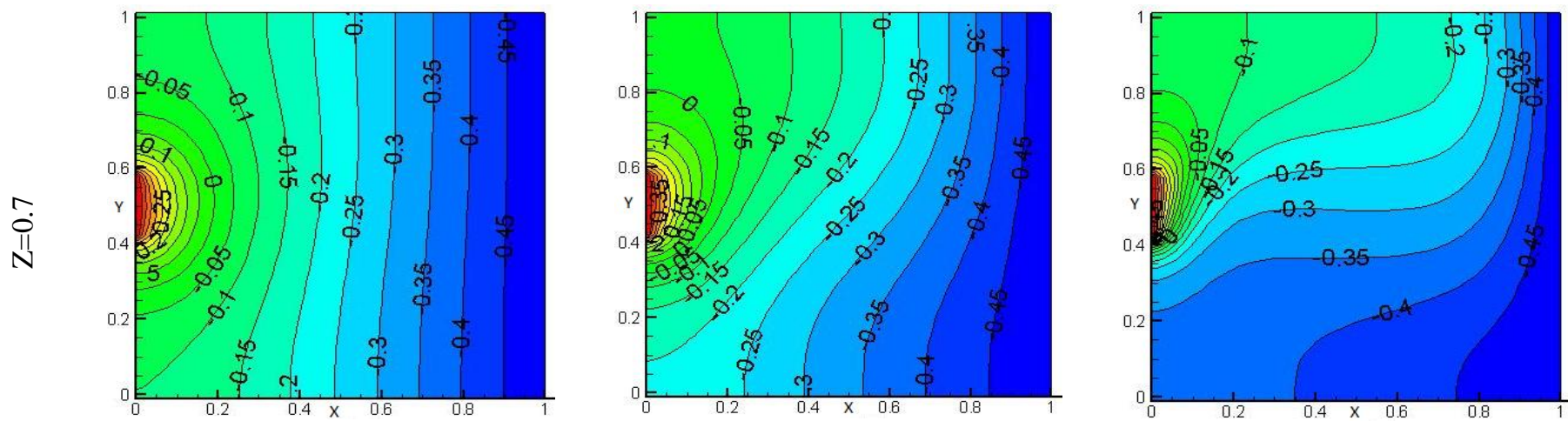

Fig 3: The isotherms for water $\mathrm{Al}_{2} \mathrm{O}_{3}$ for different $\mathrm{Z}$ plans and different $\mathrm{Ra}$. 

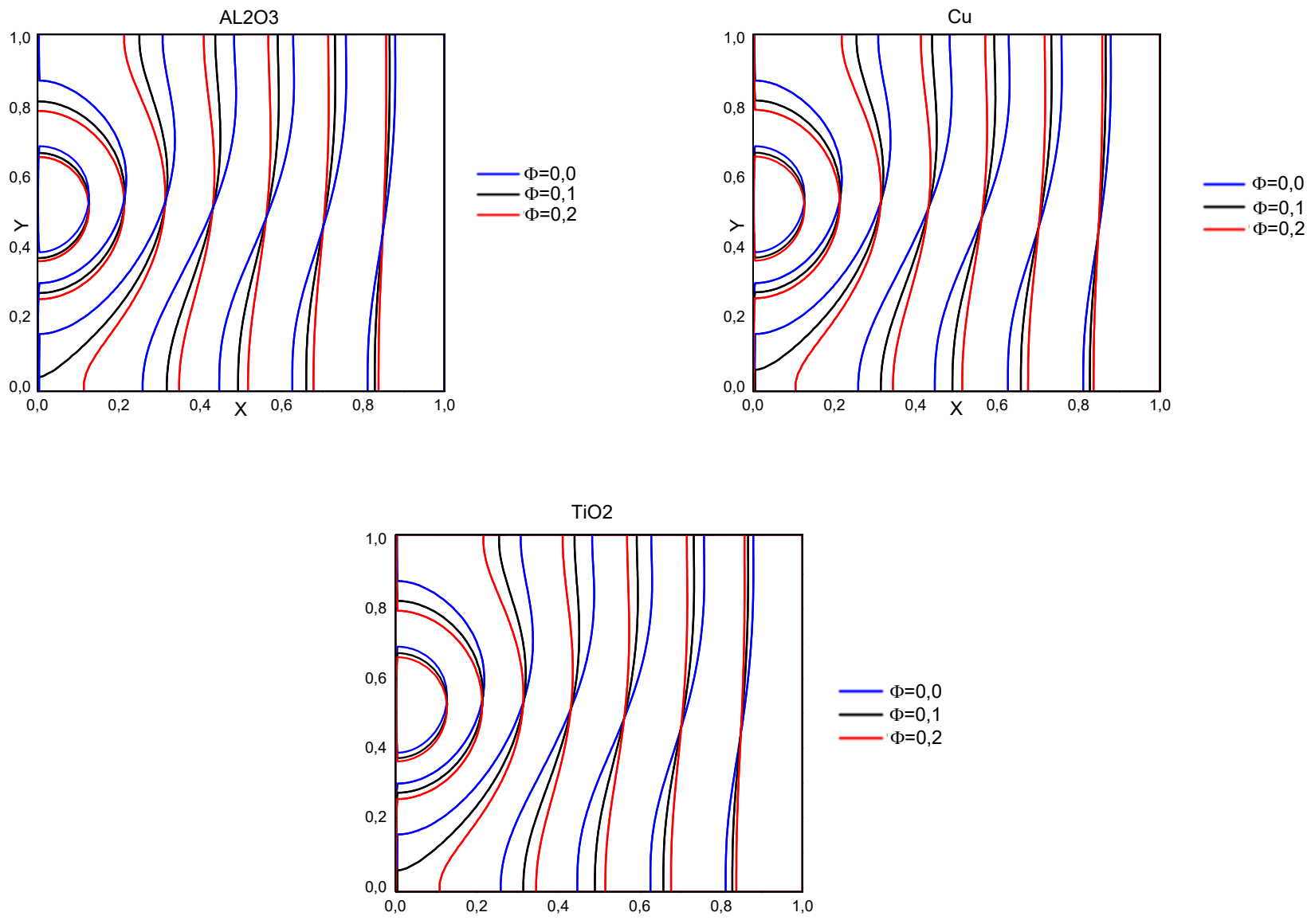

Fig 4: Temperature contours in the plan $\mathrm{Z}=0.5$, for different nanofluids and $\mathrm{Ra}=10^{3}$ with $0.0 \leq \Phi \leq 0.2$

\subsection{Velocity:}

Since the active walls of the geometry are in the $\mathrm{X}$ direction and the main vortex, induced by natural convection is in the $\mathrm{Z}$ plane; we chose the plan $\mathrm{Z}=0.5$ to present the vertical velocity profiles $\mathrm{V}_{\mathrm{y}}(0.5 \mathrm{H} ; \mathrm{Y} ; 0.5 \mathrm{H})$ and horizontal one $\mathrm{V}_{\mathrm{X}}(\mathrm{X} ; 0.5 \mathrm{H} ; 0.5 \mathrm{H})$. These profiles, shown in Fig 5, correspond to $\mathrm{Ra}=10^{3}$ and $10^{4} ; 0.0 \leq \Phi$ $\leq 0.2$ and different nanofluids.

They show a slow motion of the nanofluid compared to the pure water $(\Phi=0)$ for all the presented cases. In addition, the velocity decreases by increasing the volume fraction, for a chosen nanofluid and a fixed value of Ra.

Generally, higher values of $\mathrm{Ra}$ induces higher velocities and smaller difference between the maximum values (relative to $\Phi=0$ ) of velocity for a considered nanofluid and $\Phi$ value. Indeed, in the case of pure Water and nanofluid- $\mathrm{Al}_{2} \mathrm{O}_{3}$ and for $\mathrm{Ra}=10^{3}$, the deviation (relative to $\Phi=0$ ) between the maximum values of the horizontal speed are $\Delta \mathrm{Vmax}=18.60 \%$ for $\Phi=0.05$ and $\Delta \mathrm{Vmax}=$ $30.23 \%$ for $\Phi=0.1$. While $\Delta V \max =1.66 \%$ for $\Phi=0.05$ and $\Delta \mathrm{V} \max =4.16 \%$ for $\Phi=0.1$ in the case of $\mathrm{Ra}=10^{4}$. However for the vertical velocity, the differences between maximum values are $\Delta \mathrm{Vmax}=17.77 \%$ for $\Phi=0.05$ and $\Delta \mathrm{Vmax}=26.66$ for $\Phi=0.1$ and $\mathrm{Ra}=10^{3}$. By increasing the Rayleigh number, these deviations decrease. For $\mathrm{Ra}=10^{4}$ these deviations are $\Delta \mathrm{Vmax}=1.74 \%$ for $\Phi=0.05$ and $\Delta \mathrm{Vmax}=4.34$ for $\Phi=0.1$.

In order to highlight the velocity differences between the nanofluids, we present in Fig 6 , the vertical velocity component obtained in the plane $\mathrm{Z}=0.5, \mathrm{Ra}=10^{4}, \Phi=0.2$ and different nanoparticles $\left(\mathrm{Cu}, \mathrm{TiO}_{2}\right.$ and $\left.\mathrm{Al}_{2} \mathrm{O}_{3}\right)$. We can notice similar profiles for all the considered nanofluids. However, $\mathrm{Cu}$ nanoparticles ... a higher speed motion compared to $\mathrm{Al}_{2} \mathrm{O}_{3}$ or $\mathrm{TiO}_{2}$. This should result in a higher heat transfer rate in the case of the nanofluid water+Cu. 
$\mathrm{Ra}=10^{3}$
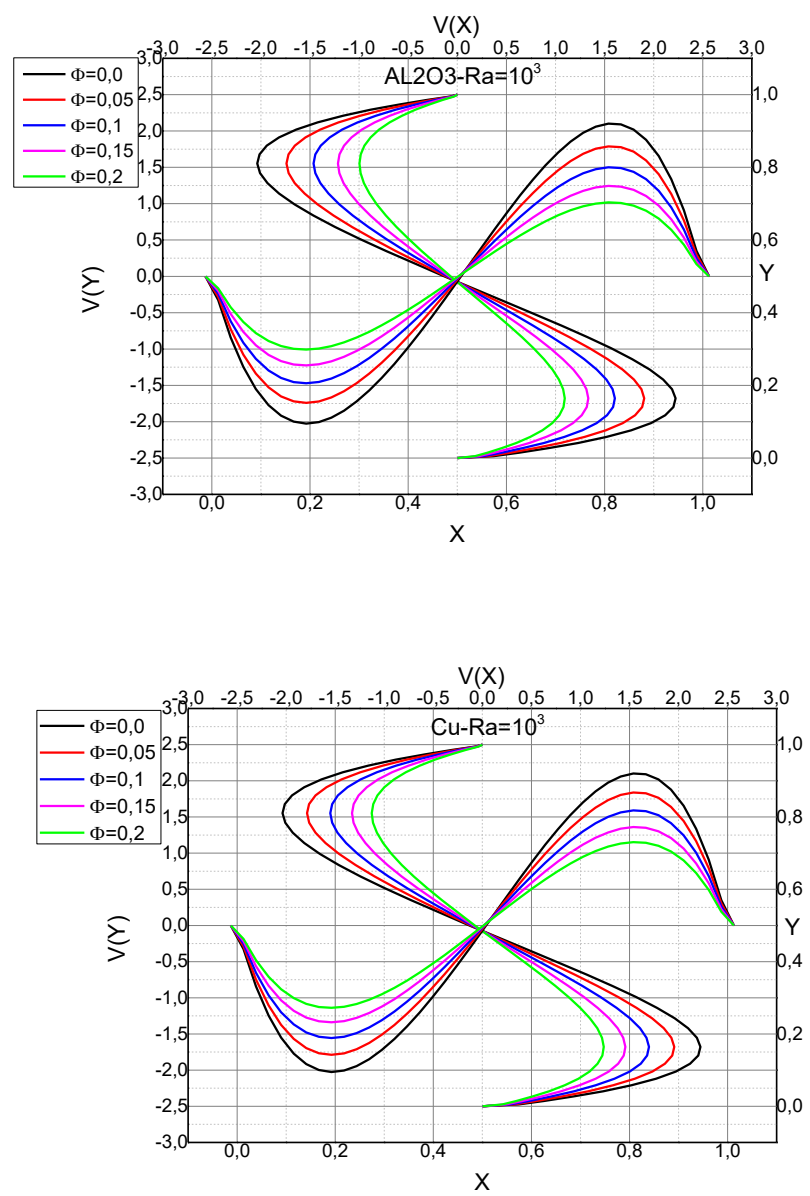

$\mathrm{V}(\mathrm{X})$

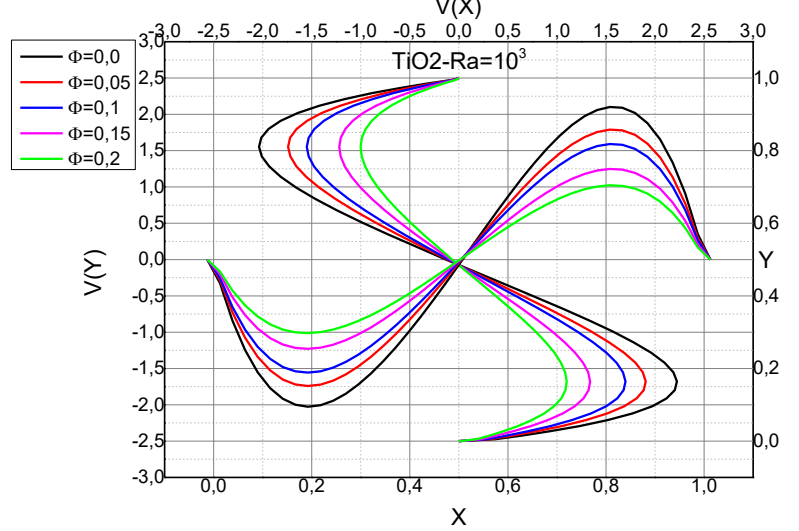

$\mathrm{Ra}=10^{4}$
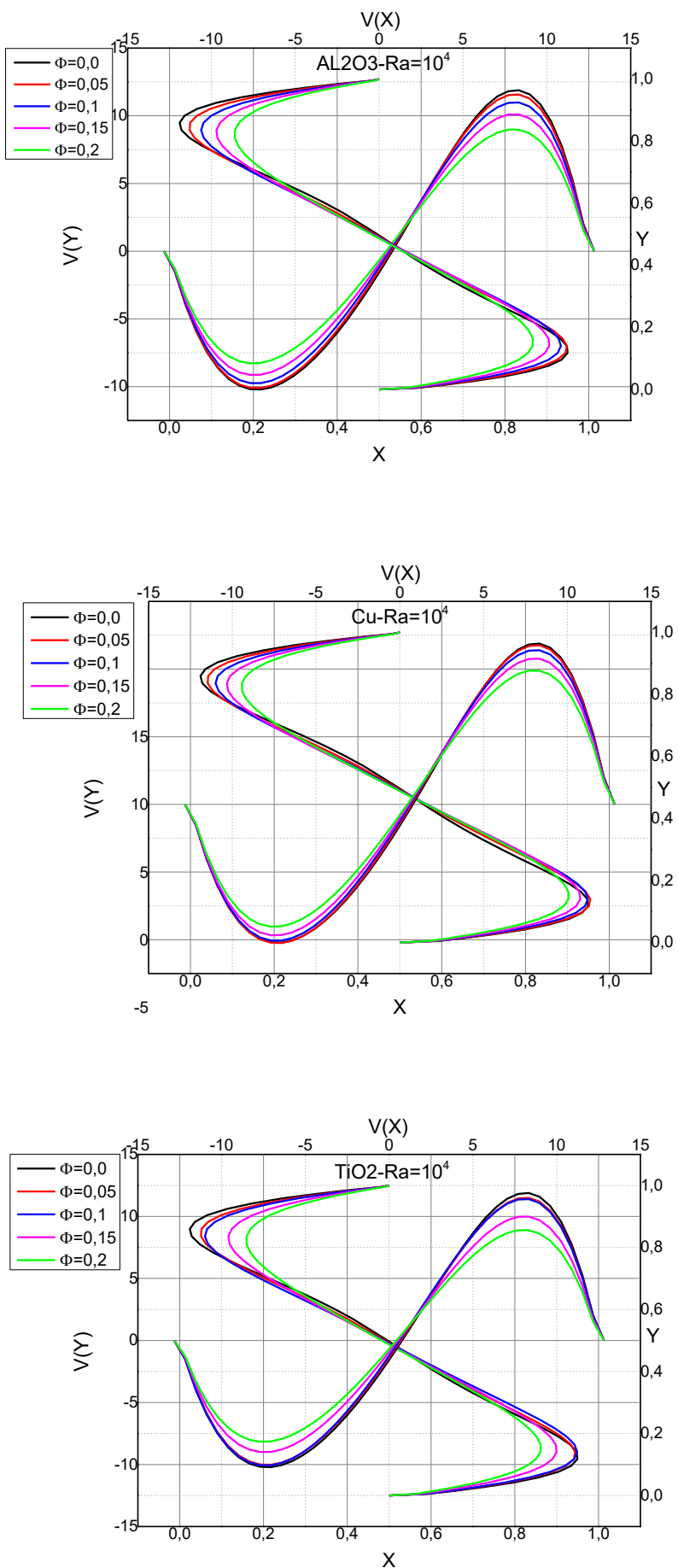

Fig 5. Speed vertical component in the plane $\mathrm{Z}=0.5$ for $\mathrm{Ra}=10^{3}, 10^{4}$ and different nanofluids 


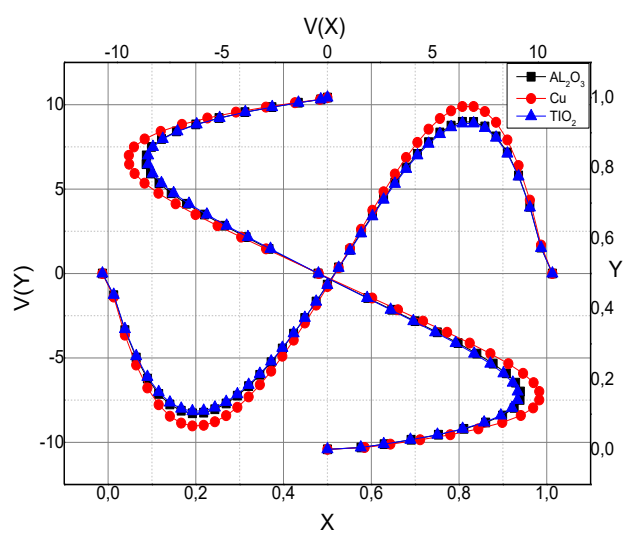

Fig 6: Profiles of the speed vertical component in the plan $\mathrm{Z}=0.5$ of different nanofluids, for $\mathrm{Ra}=10^{4}$ and $\Phi=0.2$.

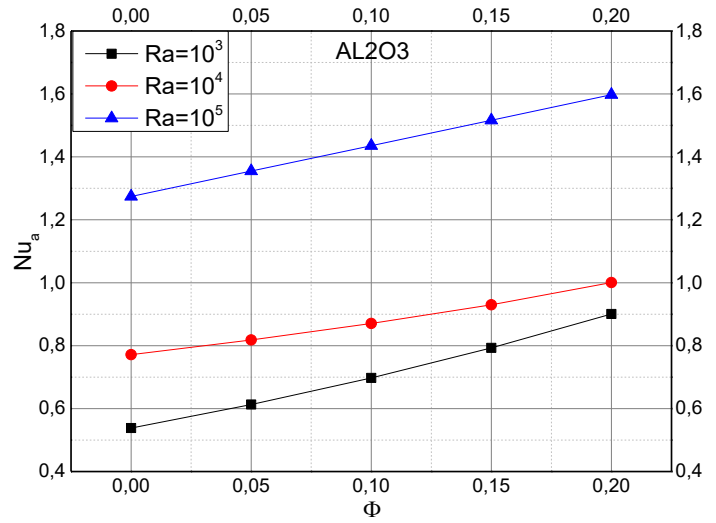

\subsection{Nusselt Number}

Fig 7 represents the variation of the average Nusselt number $\left(\mathrm{Nu}_{\mathrm{a}}\right)$ as a function of the volume fraction of $\mathrm{Cu}$ nanoparticles, $\mathrm{TiO}_{2}$ and $\mathrm{Al}_{2} \mathrm{O}_{3}$ for different values of the Rayleigh number. We note that for a volume fraction given, $\mathrm{Nu}_{\mathrm{a}}$ increases when $\mathrm{Ra}$ increases. For all values of $\mathrm{Ra}$, the average Nusselt number increases with the volume fraction in nanoparticles. This increase is due to the improvement of the thermal conductivity of the actual nanofluid, when the volume fraction of nanoparticles increases. Indeed, as shown in Table IV, the values of the average Nusselt number through are higher when the nanofluide used is based on $\mathrm{Cu}$ nanoparticles. This figure also shows the effect of the type of nanoparticles on the variation in the number of average Nusselt, the rate of transfer of heat is the maximum for the copper, which has the largest thermal conductivity by report to $\mathrm{TiO}_{2}$, and $\mathrm{Al}_{2} \mathrm{O}_{3}$.

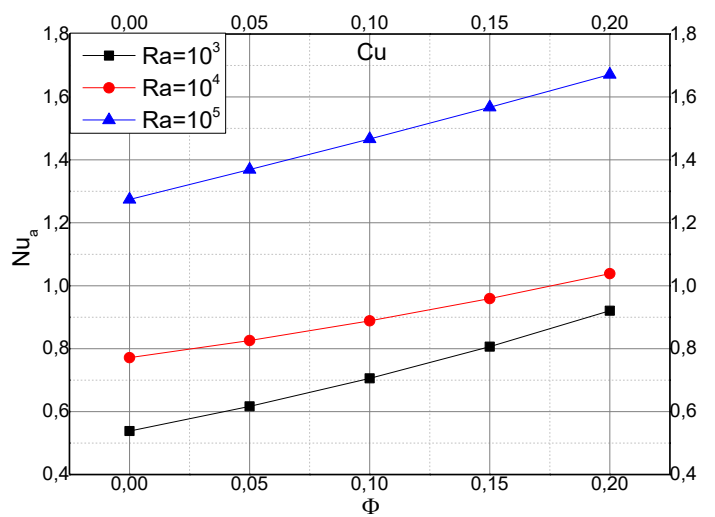

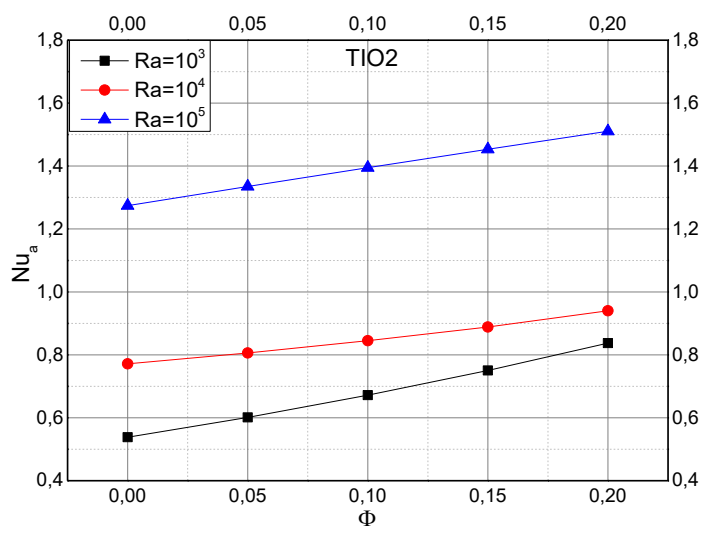

Fig 7: The variation of the average Nusselt number with Ra for different volume fraction and different nanofluids. 
Table 4: Variation of the average Nusselt with Ra for differentnanofluids.

\begin{tabular}{|c|c|c|c|}
\cline { 2 - 4 } \multicolumn{1}{c|}{} & $\mathrm{Al}_{2} \mathrm{O}_{3}$ & $\mathrm{Cu}$ & $\mathrm{TiO}_{2}$ \\
\hline $\mathrm{Ra}=10^{3}$ & 0,9005131 & 0.9205365 & 0.8371417 \\
\hline $\mathrm{Ra}=5 \times 10^{3}$ & 0,9327757 & 0.9611410 & 0.8711013 \\
\hline $\mathrm{Ra}=10^{4}$ & 1,000807 & 1.038598 & 0.9399605 \\
\hline $\mathrm{Ra}=5 \times 10^{4}$ & 1,386655 & 1.451977 & 1.310881 \\
\hline $\mathrm{Ra}=10^{5}$ & 1,597783 & 1.671166 & 1.510750 \\
\hline
\end{tabular}

\section{Conclusions}

The study of the natural convection in a three-dimensional cavity heated by two portions on its vertical wall was carried out numerically. Isotherms, fluid velocity and heat transfer have been studied. The obtained results showed the important effect of some parameters such as, the volume fraction, the nanoparticles type and the Rayleigh number. Hence, the increase of $\mathrm{Ra}$ leads to a large improvement of heat evacuated through the cavity. Similarly, the increase of the volume fraction causes an intensification of the flow and an increase of thermal exchanges. In addition, the resulting heat transfer in the case of $\mathrm{Cu}$ nanoparticles is higher than that obtained with $\mathrm{TiO}_{2}$, and $\mathrm{Al}_{2} \mathrm{O}_{3}$.

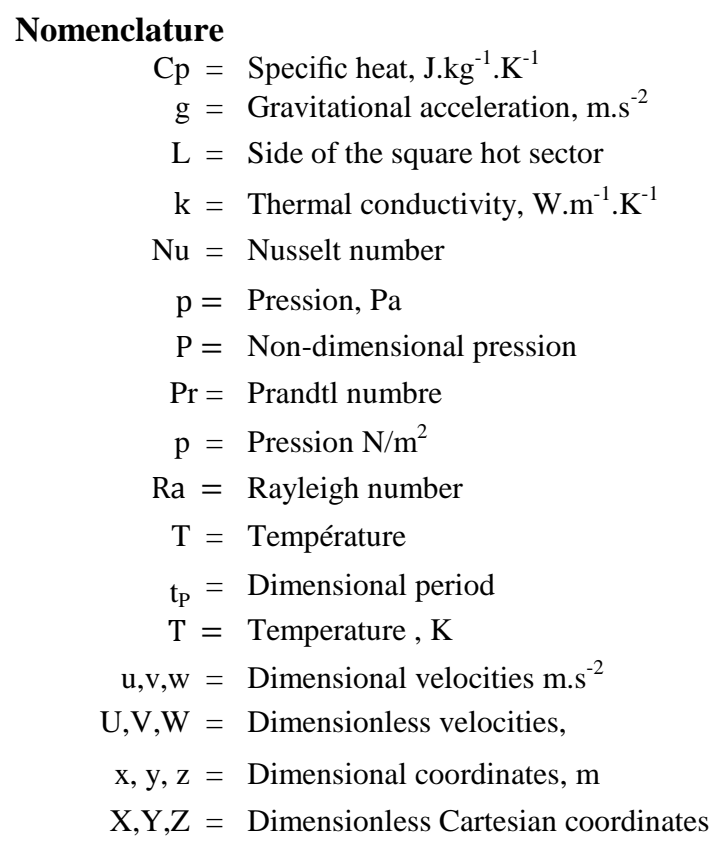

Greek symbols

$\alpha=$ Thermal diffusivity $\theta=$ Non-dimensional temperature

$\beta=$ Volumetric thermal expansion coefficient

$\Phi=$ Volumic fraction

$\mu=$ Dynamical viscosity, N.s.m ${ }^{-2}$

$v=$ Kinematic viscosity, $\mathrm{m}^{2} \cdot \mathrm{s}^{-1}$

$\rho=$ Density, $\mathrm{kg} \cdot \mathrm{m}^{-3}$

\section{Subscripts/ Exhibitors}

$\mathrm{C}=$ cold

$\mathrm{H}=$ hot

$\mathrm{f}=$ fluid (pure water)

$\mathrm{a}=$ average

$\mathrm{nf}=$ nanofluid 2

$\mathrm{np}=$ nanoparticl

\section{References}

[1] S.U.S.Choi, Enhancing Thermal Conductivity of Fluids with Nanoparticles,ASME. Fluids Engineering Division,vol.231, 1995, pp. 99-105.

[2] N.Putra, W.Roetzel,S.K.Das, Naturel convection of nanofluids, Heat and Mass Transfer, vol.39, 2003, pp. 775784.

[3] K. Khanafer, K. Vafai, M. Lightstone, Buoyancy-driven heat transfer enhancement in a two-dimensional enclosure utilizing nanofluids, International Journal of Heat and Mass transfer, vol. 46, 2003, pp. 3639-3653.

[4] H. C. Brinkman, The viscosity of concentrated suspensions and solution, Journal of Chemical Physics, vol.20, 65, 2005, pp. 863-869.

[5] F. J. Wasp, Solid-Liquid Flow Slurry Pipeline Transportation, Trans. Tech. Pub., 1977, Berlin.

[6] H. F. Oztop, E. Abu-Nada, Numerical study of natural convection in partially heated rectangular enclosures filled with nanofluids, International Journal of heat and Fluid Flow, vol. 29, 2008, pp. 1326-1336.

[7] R. Y. Jou, S. C. Tzeng, Numerical research of nature convective heat transfer enhancement filled with nanofluids in rectangular enclosures, International Communications in Heat and Mass Transfer, vol. 33, 2006, pp. 727-736.

[8] B. Ghasemi, S. M. Aminossadati, A. Raisi, Magnetic field effect on natural convection in a nanofluid-filled square enclosure, International Journal of Thermal Scinces, vol. 50, 2011, pp. 1748-1756.

[9] B.GHASEMI, S. M. AMINOSSADATI, et A. RAISI, Magnetic field effect on natural convection in a nanofluidfilled square enclosure. International Journal of Thermal Sciences, 2011, vol. 50, no 9, p. 1748-1756.

[10] H. NEMATI, M. FARHADI, K. SEDIGHI, et al. Magnetic field effects on natural convection flow of nanofluid in a rectangular cavity using the Lattice Boltzmann model. Scientia Iranica, 2012, vol. 19, no 2, p. 303-310.

[11] MAHMOUDI, Amir Houshang, SHAHI, Mina, RAOUF, Abbas Honarbakhsh, et al. Numerical study of natural convection cooling of horizontal heat source mounted in a square cavity filled with nanofluid. International Communications in Heat and Mass Transfer, 2010, vol. 37, no 8, p. 1135-1141.

[12] J. GUIET, M. REGGIO, et P. VASSEUR, Natural convection of nanofluids in a square enclosure with a 
protruding heater. Advances in Mechanical engineering, 2012, vol. 4, p. 167296.

[13] J. RAVNIK, L. ŠKERGET, et M. HRIBERŠEK, Analysis of three-dimensional natural convection of nanofluids by BEM. Engineering Analysis with Boundary Elements, 2010, vol. 34, no 12, p. 1018-1030.

[14] XUAN, Yimin et ROETZEL, Wilfried. Conceptions for heat transfer correlation of nanofluids. International Journal of heat and Mass transfer, 2000, vol. 43, no 19, p. 3701-3707.

[15] MAXWELL, James Clerk. A treatise on electricity and magnetism. Clarendon press, 1881.

[16] PATANKAR, Suhas. Numerical heat transfer and fluid flow. CRC press, 1980.

[17] PATANKAR, V. Suhas et D. SPALDING, Brian. A calculation procedure for heat, mass and momentum transfer in three-dimensional parabolic flows.International journal of heat and mass transfer, 1972, vol. 15, no 10, p. 1787-1806.

[18] BEN-CHEIKH, Nader, CHAMKHA, J. Ali, BEN-BEYA, Brahim, Taieb Lili. Natural Convection of Water-Based Nanofluids in a Square Enclosure with Non-Uniform Heating of the Bottom Wall. Journal of Modern Physics, 2013, Vol.4 No.2, p.147-159.

\section{AUTHORS' INFORMATION:}

Mohamed SANNAD ${ }^{1}$ was born in Gulmim, Morocco. I received a License degree from FSA, Ibn Zohr University Agadir, and a master degree from ENSA School, Ibn Zohr University Agadir in 2014. I am a PhD student in engineering science at ENSA School, Ibn Zohr University Agadir, Morocco.

Btissam Abourida ${ }^{2}$ is currently a Professor at the Energy and environment engineering process department of National School of Applied sciences (ENSA), Ibn Zohr University, Agadir, Morocco, since 2008. She received her PhD degree in 1999 at cadi Ayyad University (Morocco), in Energy specialty. Her current research interests heat transfer phenomenon and renewable energy. She is responsible of energy and transfer phenomenon research team at ENSA.

Lahoucine Belarche ${ }^{3}$ was born in Tiznit, Morocco. He received a License degree from ENSET School, Mohamed 5 Souissi University Rabat, and a master degree from ENSA School, Ibn Zohr University Agadir in 2010. He is currently Doctor Researcher in Computational fluid dynamics and thermal simulation engineering research at ENSA School, Ibn Zohr University Agadir, Morocco.

Hicham. Doghmi ${ }^{4}$ was born in Sidi Slimane, Morocco. He received Technical University degree at high school of technology fes professional license université moulay abdellah fes, and a master degree from ENSA School, Ibn Zohr University Agadir in 2014. He is a PhD student in engineering science at ENSA School, Ibn Zohr University Agadir, Morocco. 